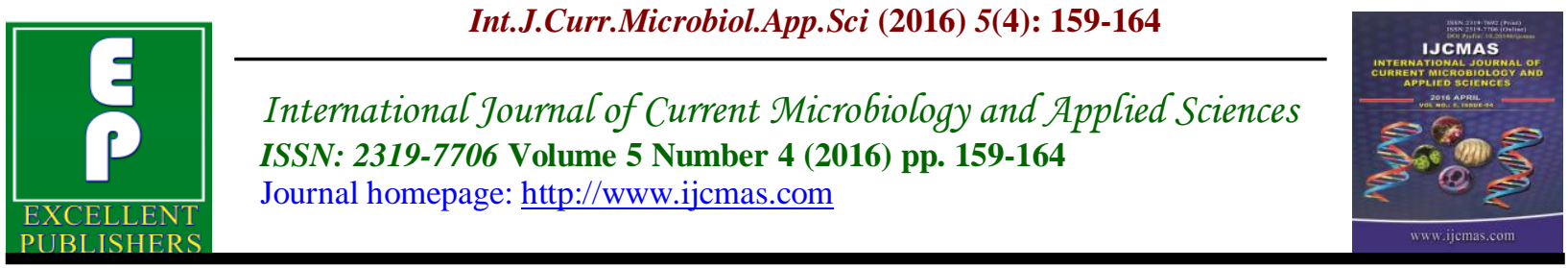

Original Research Article

http://dx.doi.org/10.20546/ijcmas.2016.504.020

\title{
Speciation and Detection of Virulence Factors of Coagulase Negative Staphylococci Isolated from Various Clinical Samples
}

\author{
K. Punitha Valli, S. Pramodhini*, S. Umadevi and K. S. Seetha \\ Department of Microbiology, Mahatma Gandhi Medical College and Research Institute, \\ Sree Balaji Vidyapeeth University, Puducherry, India \\ *Corresponding author
}

\section{A B S T R A C T}

Keywords

CoNS,

Slime

production,

DNAse,

Haem-

agglutination.

\section{Article Info}

Accepted:

14 March 2016

Available Online:

10 April 2016
Coagulase negative Staphylococci (CoNS), previously dismissed as contaminants are now emerging as important potential pathogens with the increase in number of severely debilitated patients and increased use of implants in hospitals. The objectives of this study are to isolate, speciate and to detect various virulence factors of CONS from various clinical samples. A total of 500 various clinical samples from blood, urine, pus, central line tip and UVC tip were studied for a period of one year. Out of which, 62 isolates of clinically significant, non repetitive coagulase negative Staphylococci were identified by standard biochemical test. Following identification and speciation, the organism was studied for various virulence factors like Slime production, DNAse and Haemagglutination. A total of $62 \mathrm{CoNS}$, isolated from 500different clinical samples. Among various species of CoNS,S. epidermidis was most frequently isolated, corresponding to 20 (32.3\%) isolates. Most of the isolates were positive for slime production (72.6\%). Production of DNAse and Haemagglutination activity were shown in $43.5 \%$ and $33.9 \%$ respectively. Because of the increasing clinical significance of CoNS, accurate species identification of CoNS is highly desirable to permit a more precise determination of host-pathogen relationship of CoNS and to report them as human pathogen.

\section{Introduction}

Coagulase negative Staphylococci (CoNS), more commonly accounted as contaminants are now considered as a important potential pathogens with increase in use of implants and with the increase in frequency and number of severely debilitated patients. More than 30 species of CONS are recognised but only a few are commonly incriminated in human infections.
Although CoNS were long considered nonpathogenic and having few virulence factors, new factors have lately been determined in the period of gradual clarification of pathogenesis. The majority of known factors are incorporated into the biofilm formation (Longuaerova, 2006). Production of biofilm by coagulase negative Staphylococci especially in higher incidence by $S$. 
epidermidis is noted in indwelling medical devices and implants.

Although coagulase negative species other than S.epidermidis and S.saprophyticus are frequently found as contaminants in clinical specimens, several other species have now been reported as cause of human infection, principally in wounds, urinary tract infections, bacteremia, osteomyelites, catheter related sepsis, ventriculo-peritoneal shunt infection and both native-valve and prosthetic-valve endocardities.The more commonly implicated other species include S.hemolyticus, S.lugdunensis,.schleiferi, S.warneri, S.hominis, S.simulans and S.sacchrolyticus etc.

Evidence indicates that pathogencity might be related to the slime production and several other extra cellular enzymes to combat the host defense mechanism.The objectives of this study are to isolate, speciation and to detect various virulence factors of CONS isolated from clinical samples.

\section{Materials and Methods}

A total of 500 clinical samples such as blood, urine, pus, central line tip and UVC tip were collected for a period of one year. Out of which, 62 isolates of clinically significant, non repetitive coagulase negative Staphylococci were isolated and identified by standard biochemical test.

\section{Characterization of Coagulase Negative Staphylococci}

The following test such as phosphatase production, acetoin production, ornithine decorboxylation, sugars (mannitol, trehalose, xylose, maltose, mannose, sucrose, lactose) fermentation test, novobiocin and polymyxin B (50 unit) sensitivity test were done to speciate coagulase negative Staphylococci.(Koneman et al.,1997)The organism were further subjected for detection of various virulence factors like Slime production, DNAse and Haemagglutination.

\section{Detection of Virulence Factor}

\section{Slime Production}

Slime producing ability of the CoNS were determined by using the congo red agar (CRA) method (Freeman et al., 1989). Congo red agar is prepared by making aqueous solution of congo red $0.8 \mathrm{~g} / \mathrm{l}$ and autoclaved separately $\left(121^{\circ} \mathrm{C}\right.$ for 15 minutes) and cooled. It was added to the cooled agar base containing brain heart infusion broth $37 \mathrm{~g} / \mathrm{l}$, sucrose $50 \mathrm{~g} / \mathrm{l}$, and agar $10 \mathrm{~g} / \mathrm{l}$.

Several colonies of single isolates were inoculated on medium and incubated aerobically at $37^{\circ} \mathrm{C}$ for $24 \mathrm{hrs}$. Isolates which produced black colonies with dry crystalline consistency were regarded as slime positive. Non slime producer usually remains pink.

\section{DNAse Test}

This test was performed by spot inoculating the isolates on the DNAse agar and incubated at $37^{\circ} \mathrm{C}$ for 4 days. After incubation $1 \mathrm{~N} \mathrm{HCl}$ was poured on the agar. Clear halo around the bacterial growth was considered as positive (Deighton et al., 1988).

\section{Haemagglutination Test}

The test was performed in U shaped micro titre well. Individual CONS isolates were added in to the phosphate buffer saline (PBS) and adjust the turbidity to McFarland standard1. Two serial dilutions of the 
bacterial suspension were made in the microtiter plates to give a total volume of 50 $\mu 1$ per well. Then, $50 \mu \mathrm{l}$ of the $1 \%$ human erythrocyte suspension in PBS was added to each well. After shaking, the plates were incubated at room temperature for 2 hours and the hemagglutination was recorded as positive or negative. (Rupp and Archer, 1992).

\section{Results and Discusssion}

A total of 62 CoNS, were isolated from 500 different clinical samples. CoNS were most commonly isolated from Pus (40.3\%), followed by urine (29\%), blood(24.2\%) and least isolated from indwelling devices like central line tip $(4.8 \%)$ and UVC tip (1.6\%) (Table 1)

Among the CoNs species, S. epidermidis was most frequently isolated, corresponding to $20(32.3 \%)$ isolates. The remaining species isolated were $S$. haemolyticus (15 isolates, 24.2\%), S.saprophyticus (9 isolates, $14.5 \%), S$. lugdunensis (7 isolates, 11. 3\%), S. hominis (7 isolates, $11.3 \%$ ), S. schlieferi (2 isolates, 3.2\%), S. warneri (1 isolates, $1.6 \%)$, and $S$. warneri (1 isolate, $1.6 \%$ ).(Table 2)

Detection of virulence factors of CoNS species are shown in Table 3. Most of the isolates were positive for slime production
(72.6\%). Production of DNAse and Haemagglutination activity were shown in $43.5 \%$ and $33.9 \%$ respectively.

Coagulase-Negative Staphylococci are normal flora component of various part of slin and mucosa of respiratory and gastrointestinal tract were considered as contaminants bacteria formerly, but are now considered as important possible pathogens. As opposed to Staphylococcus aureus, though there are not equipped with various virulence factors they tend to establish infection when there is a breach in external barrier due trauma, wounds, inoculation and implantation of foreign bodies.

In this study, overall prevalence of clinically significant CoNS isolated from various clinical samples were 62/500 (12\%) similar isolation rate of $14.4 \%$ and $17.5 \%$ were reported in various other studies (Sarathbabu et al., 2013; Javadpour et al., 2010).

In the current study, CoNS were predominantly isolated from pus sample $(40 \%)$ followed by urine $(29 \%)$. In another similar study, isolation rate of CoNS were $32(33.3 \%)$ from pus and 26(27.1\%) from the urine samples (Asangi et al., 2011). Few others also have reported $30 \%$ (Zilevica et al., 2005) and 35.5\% (Villari et al., 2000) isolation rate from pus.

Table.1 Number of Cons Isolated from Clinical Samples

\begin{tabular}{|l|l|l|l|l|l|l|}
\hline Total & Total no of & \multicolumn{3}{|l|}{ Clinical Samples } \\
\cline { 2 - 7 } $\begin{array}{l}\text { no of } \\
\text { Samples }\end{array}$ & $\begin{array}{l}\text { CoNS } \\
\text { Isolated (\%) }\end{array}$ & Pus (\%) & Urine (\%) & Blood (\%) & $\begin{array}{l}\text { Central } \\
\text { line tip (\%) }\end{array}$ & $\begin{array}{l}\text { UVC tip } \\
(\%)\end{array}$ \\
\hline 500 & $62(12.4 \%)$ & $25(40.3 \%)$ & $18(29 \%)$ & $15(24.2 \%)$ & $3(4.8 \%)$ & $1(1.6 \%)$ \\
\hline
\end{tabular}


Table.2 Species Distribution of CoNS Species from Various Clinical Samples(n=62)

\begin{tabular}{|l|l|l|l|l|l|l|}
\hline Isolates & $\%$ & Blood & Urine & Wound & $\begin{array}{l}\text { Central } \\
\text { line tip }\end{array}$ & $\begin{array}{l}\text { UVC } \\
\text { tip }\end{array}$ \\
\hline S.epidermidis (20) & 32.3 & 4 & 3 & 10 & 2 & 1 \\
\hline S.haemolyticus (15) & 24.2 & 4 & 6 & 4 & 1 & - \\
\hline S. saprophyticus(9) & 14.5 & 1 & 4 & 4 & - & - \\
\hline S.hominis(7) & 11.3 & 1 & 3 & 3 & - & - \\
\hline S.lugdunensis(7) & 11.3 & 4 & 1 & 2 & - & - \\
\hline S. schlieferi(2) & 3.2 & 1 & - & 1 & - & - \\
\hline S.cohini(1) & 1.6 & - & - & 1 & - & - \\
\hline S.warneri(1) & 1.6 & - & 1 & - & - & - \\
\hline
\end{tabular}

Table.3 Detection of Slime Production, DNAse and Haemagglutination from CoNS

\begin{tabular}{|l|l|l|l|}
\hline Isolates & $\begin{array}{l}\text { No of slime } \\
\text { production } \\
\text { positive }\end{array}$ & $\begin{array}{l}\text { No of DNAse } \\
\text { positive }\end{array}$ & $\begin{array}{l}\text { No } \\
\text { haemagglutination } \\
\text { Positive }\end{array}$ \\
\hline S.epidermidis (20) & 17 & 5 & 11 \\
\hline S.haemolyticus(15) & 12 & 9 & 5 \\
\hline S.saprophyticus(9) & 6 & & 3 \\
\hline S.hominis(7) & 3 & 5 & - \\
\hline S.lugdunensis(7) & 4 & 2 & 2 \\
\hline S.schlieferi(2) & 2 & 1 & - \\
\hline S.cohini(1) & - & - & - \\
\hline S.warneri(1) & 1 & - & - \\
\hline Total(62) & $\mathbf{4 5 ( 7 2 . 6 \% )}$ & $\mathbf{2 7 ( 4 3 . 5 \% )}$ & $\mathbf{2 1 ( 3 3 . 9 \% )}$ \\
\hline
\end{tabular}

S. epidermidis was the CoNS species most frequently isolated, corresponding to 20 $(32.3 \%)$ isolates. The remaining species were distributed among $S$. haemolyticus (15 isolates, $24.2 \%)$, S.saprophyticus ( 9 isolates, $14.5 \%)$, S. lugdune nsis (7 isolates, 11.3\%), S. hominis (7 isolates, $11.3 \%)$, S. schlieferi (2 isolates, $3.2 \%)$, S. warneri (1 isolates, $1.6 \%)$, and $S$. warneri (1 isolate, $1.6 \%$ ).

Staph. epidermidis was the most common species identified, accounting for $32.3 \%$ of isolates. Staph. haemolyticus was the second most common species, followed by Staph. Saprophyticus, Staph. hominis and, Staph. lugdunensis which was well in concordance with various other studies (Goyal et al., 2006; Sharma et al., 2010; Surekha et al., 2011).

The most important pathogenic mechanism of CoNS in establishing disease in human in foreign bodies is due to their biofilm forming capacity. Biofilm is an extracellular polysaccharide produced by these microorganisms which permits them to adhere to smooth plastic surfaces, colonizing catheters and prosthetic devices pacemakers. (Vogel et al., 2000).

Detection of biofilm production showed $72.6 \%$ of the isolates were slime producers 
well comparable to similar study.(Azuka Azih et al., 2013) where they reported $75.95 \%$ of all CoNS species were positive for slime production.

Though DNase is not entirely reliable indicator of pathogenicity of CoNS, it was reported that CoNS also have DNase activity (Quinn et al., 1994). In this study, the rate of DNase positiveness was $43.5 \%$. This results was parallel with the various other studies on DNAse activity (Rkyilmaz et al., 2006; Daghistani et al., 2000).

In our study, hemagglutination rates was 33.9\%. Study by Rkyilma et al. 2006 and Rupp et al. 1992 reported $41.1 \%$ and 33\% positivity for hemagglutination wellin concordance with our study.

In conclusion, in our study, Staph. epidermidis was the most common species identified among CoNS and $>70 \%$ were biofim producers. Increasing clinical significance of CONS as an important cause of opportunistic and nosocomial pathogen, necessitates the need to isolate and characterize Coagulase negative Staphylococci so as to report them as pathogen in causing human disease.

\section{References}

Asangi, S.Y., Mariraj, J., Sathyanarayan, M.S., Nagabhushan, Rashmi. 2011. Speciation of clinically significant Coagulase Negative Staphylococci and their antibiotic resistant patterns in a tertiary care hospital. Int. J. Biol. Med. Res., 2(3): 735-9.

Azuka Azih, A., Enabulele, I. 2013. Species Distribution and Virulence Factors of Coagulase Negative Staphylococci Isolated From Clinical Samples From the University of Benin Teaching
Hospital, Edo State, Nigeria. J. Nat. Sci. Res., 3(9): 38-43.

Daghistani, H.I., Issa, A.A., Shehabi, A.A. 2002. Frequency of nasal and wound isolates of Staphylococcus aureus associated with TSST-1 production in Jordanian population. FEMS Immunol. Med. Microbiol., 27: 95-98. Deighton, M.A., Flanklin, J.C., Spicer, W.J., Balkau, B. 1988. Species identification, antibiotic sensitivity and slime production of coagulasenegative staphylococci isolated from clinical specimens. Epidemiol. Infect., 101: 99-113.

Freeman, D.J., Falkiner, F.R., Keane, C.T. 1989. New method for detecting slime producing by coagulase negative staphylococci. J. Clin. Pathol., 42: 872-874.

Goyal, R., Singh, N.P., Kumar, A., Kaur, I., Singh, M., Sunita, N., Mathur, M. 2006. Simple and Economical Method For Speciation And Resistotyping Of Clinically Significant Coagulase Negative Staphylococci. Indian J. Med. Microbiol., 24(3): 201-4.

Javadpour, S., Karimi, E., Karmostaji, A. 2010. Frequency and anti-biogram pattern of coagulase negative Staphylococcus in clinical specimens of Shahid Mohammadi Hospital in patients, Bandar-Abbas, Iran. African J. Microbiol. Res., 4(14): 1581-3.

Koneman, E.W., Allen, S.D., Janda, W.M., Schrenkenberger, P.C., Washington, Winn, W.C. Jr. 1997. Colour Atlas and Textbook of Diagnostic Microbiology, 5th ed. Lippincott Williams \& Wilkins, PA

Longuaerova, A. 2006. Coagulase negative staphylococci and their participation in pathogenesis of human infection. Bartisk lek Listy, 107(11-12): 448452. 
Quinn, P.J., Carter, M.E., Markey, B.K., Cartey, G.E. 1994. Clinical Veterinary Microbiology. Section 2. Bacteriology, 8.Staphylococcus species. Mosby-Year Book Europe Limited, Lynton House, London, England. 118-126.

Rkyilmaz, S.T., Kaya, O. 2006. Determination of some Virulence Factors in Staphylococcus Spp.Isolated from Various Clinical Samples. Turk. J. Vet. Anim. Sci., 30: 127-132.

Rupp, M.E., Archer, G.L. 1992. Hemagglutination and adherence to plastic by Staphylococcus epidermidis. Infect. Immun., 60: 4322-4327.

Sarathbabu, Rajkumari, N., Ramani, T.V. 2013. Characterization of Coagulase negative Staphylococci isolated from urine, pus, sputum and blood samples. Int. J. Pharma. Sci. Invention, 2(1): 37-46.

Sharma, V., Jindal, N., Devi. 2010. Prevalence of methicillin resistant coagulase negative staphylococci in a tertiary care hospital Iran. $J$. Microbiol., 2(4): 185-188.

Surekha, Y.A., Mariraj, J., Sathyanarayan, M.S., Nagabhushan, Rashmi. 2011. Speciation of clinically significant Coagulase Negative Staphylococci and their antibiotic resistant patterns in a tertiary care hospital. Int. J. Biol. Med. Res., 2(3): 735-739.

Villari, P., Sarnataro, C., Iacuzio, L. 2000. Molecular epidemiology of Staphylococci epidermidis in a neonatal intensive care unit over a three-year period., J. Clin. Microbiol., 38: 1740-6.

Vogel, L., Jacobus, H.S., Sparagaren, J., Suiker, T., Dijkshoorn, L. 2000. Biofilm production byStaphylococcus epidermidis isolates associated with catheter related bacteremia. Diagnostic Microbiol. Infect. Dis., 30: 138-141.

Zilevica, A., Tracevska, T., Viesturs, M. 2005. Biotechnological methods for Precise diagnosis of methicillin resistance in Staphylococci. Bioautomation, 2: 54-64.

\section{How to cite this article:}

Punitha Valli, K., S. Pramodhini, S. Umadevi and Seetha, K. S. 2016. Speciation and Detection of Virulence Factors of Coagulase Negative Staphylococci Isolated from Various Clinical Samples. Int.J.Curr.Microbiol.App.Sci. 5(4): 159-164. doi: http://dx.doi.org/10.20546/ijcmas.2016.504.020 